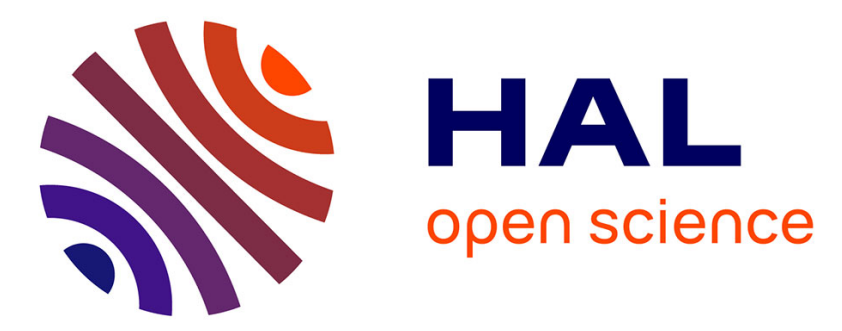

\title{
Application of the Spark Plasma Sintering Technique to Low-Temperature Copper Bonding
}

Bassem Mouawad, Maher Soueidan, D. Fabregue, Cyril Buttay, Bruno Allard, Vincent Bley, Hervé Morel, Christian Martin

\section{- To cite this version:}

Bassem Mouawad, Maher Soueidan, D. Fabregue, Cyril Buttay, Bruno Allard, et al.. Application of the Spark Plasma Sintering Technique to Low-Temperature Copper Bonding. IEEE Transactions on Components and Packaging Technologies, 2012, 2 (4), pp.553 - 560. 10.1109/TCPMT.2012.2186453 . hal-00672244

\section{HAL Id: hal-00672244 \\ https://hal.science/hal-00672244}

Submitted on 20 Feb 2012

HAL is a multi-disciplinary open access archive for the deposit and dissemination of scientific research documents, whether they are published or not. The documents may come from teaching and research institutions in France or abroad, or from public or private research centers.
L'archive ouverte pluridisciplinaire HAL, est destinée au dépôt et à la diffusion de documents scientifiques de niveau recherche, publiés ou non, émanant des établissements d'enseignement et de recherche français ou étrangers, des laboratoires publics ou privés. 


\title{
Application of the Spark Plasma Sintering Technique to Low-Temperature Copper Bonding
}

\author{
Bassem Mouawad, Maher Soueidan, Damien Fabrègue, Cyril Buttay, Member, IEEE, Bruno Allard Senior \\ Member, IEEE, Vincent Bley, Hervé Morel Senior Member, IEEE and Christian Martin Member, IEEE
}

\begin{abstract}
Planar structures, in which a power die is soldered on a substrate and wirebonds are used to connect the top of the die with the substrate, are limited in terms of thermal management and power density. Three-dimensional packaging techniques have been proposed to overcome these limits. Here, an innovative copper-to-copper bonding solution is presented, that can be used for 3-D packaging. The bonding process is described and the effect of the bonding parameters is investigated. It is found that this technique is compatible with the requirements of power electronic packaging. A test assembly including a silicon power die and ceramic substrates is presented.
\end{abstract}

Index Terms-semiconductor device packaging, power electronics, Spark Plasma Sintering, Three-dimensional packaging.

\section{INTRODUCTION}

$\mathbf{P}$ OWER SEMICONDUCTOR DEVICES have largely improved since they were first introduced more than 50 years ago. The recent availability of silicon carbide $(\mathrm{SiC})$ devices as a replacement of the classical silicon-based components has pushed the boundaries even further in terms of power density, conversion efficiency, switching speed or thermal capability.

Classically, several power dies are assembled into modules such as described in figure 1(a). Such a package provides the electrical interconnects (via the wirebonds and the copper tracks of the ceramic substrate), the electrical insulation (using the ceramic substrate), and the thermal management (the heat dissipated by the devices is removed through the ceramic layer - This structure is used in the vast majority of the power modules that are currently manufactured.

However, this planar packaging solution has become the limiting factor of the performances of the semiconductor modules. The use of wirebonds, which have a stray inductance that can exceed $10 \mathrm{nH}$ [1], increases the switching losses of the devices and limits the plain usage of the semiconductor area as well as the switching frequency. From a thermal point of view, with a classical "planar" package, all the power dissipated by a device is evacuated through its bottom side only. A cooling

January 16, 2012

Mr Mouawad, Soueidan, Buttay, Allard and Morel are with the Université de Lyon, F-69621 France, CNRS UMR 5005, INSA Lyon, Laboratoire Ampère, bât. L. de Vinci, 21, avenue Capelle, F-69621, Villeurbanne. Mr Fabrègue is with the Université de Lyon, INSA de Lyon, MATEIS-UMR 5510, Bât. Saint-Exupéry, 25 avenue J. Capelle, F-69621 Villeurbanne Cedex, France. Mr Bley is with the Université de Toulouse, LAPLACE, Université Paul Sabatier, CNRS, UMR5213, Toulouse, F-31062, France. Mr Martin is with the Université de Lyon, F-69622 France, CNRS UMR 5005, Université Claude Bernard Lyon 1, Laboratoire Ampère, bât. Omega, 43, boulevard du 11 novembre, F-69622, Villeurbanne. system that could remove the heat through both sides of the die would be much more efficient.

Replacing the planar structure and its wirebond interconnects is not an easy task, as it is a very mature solution. Many research groups are working on alternative architectures, some focusing on replacing the wirebonds by a flex substrate [2], or with a screen-printed paste [3]. Other researchers have worked on so-called "sandwich structures", which use two similar substrates with the dies in-between. These solutions are designed to offer double-side cooling of the devices [4], [5]. Several papers have been dedicated to the comparison of the various 3-D structures [6]-[8].

\section{Presentation of the 3-D structure}

\section{A. Description}

As mentioned in the previous section, a three-dimensional (as opposed to planar) structure is needed to take full advantage of the power devices. A possible solution for such a package is depicted in figure 1(b) [9]. The originality of the presented technique is that copper posts (or pillars) are grown electrochemically on the die. These posts are then bonded to a Direct Bonded Copper (DBC) substrates on both sides. DBC is basically a ceramic tile with two layers of copper, one of them being patterned to form an electrical circuit.

Such a structure offers double-side cooling capability. Furthermore, using copper posts instead of a single, massive interconnect should give more freedom for the system to accommodate the thermal expansion of copper (which is $17 \mathrm{ppm} / \mathrm{K}$, as compared to less than 4 for $\mathrm{Si}$ or $\mathrm{SiC}$ ). One of the advantages of this technique is that we can set the height of the posts to insure sufficient spacing between the DBC tiles and the die. This is required to sustain the required voltage (1200 V or more).

Another advantage of the post structure is that it can accept dies of different thicknesses in the same package, by varying the height of the posts.

However, this "micro-posts" structure has a drawback: the effective interconnect area is smaller than in the case of a single, massive post. With the current design, the copper posts only represent $25 \%$ of the die contact area (the remaining $75 \%$ is the space around the posts). From an electrical point of view, this area is sufficient as it is already more than what is attainable using wirebonds. From a thermal point of view, however, a special care must be given to achieve a low thermal resistance. In particular, only materials with a very high thermal conductivity should be used for the interconnections, 


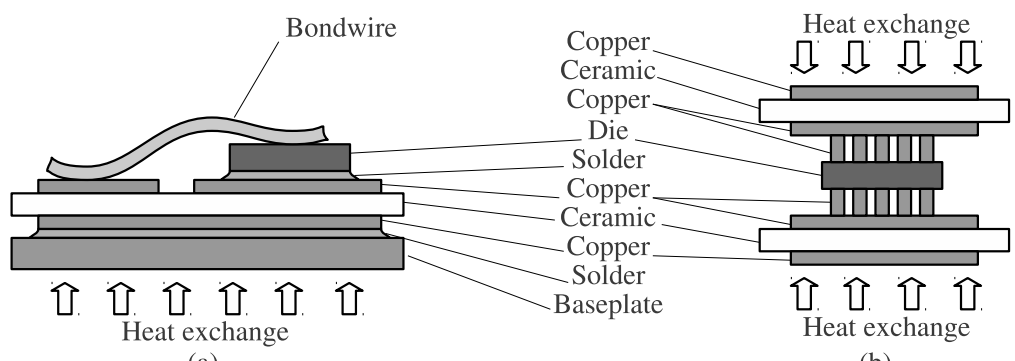

(a)

(b)

Fig. 1. A planar module (a) and the proposed "3D" structure based on micro-posts, which offers double-side cooling

including the bonding between the posts and the DBCs. There is an interest to remove the inner bonding material. For this reason, it was decided to develop a special direct copper-tocopper bonding technique.

\section{B. Fabrication}

The first step to achieve a structure such as described in figure 1(b) is to grow copper posts on the semiconductor die. This is described in details in [9]. Thin $\mathrm{Ti}$ and $\mathrm{Cu}$ layers (20/100 $\mathrm{nm}$ respectively) are deposited on the aluminium pad of a die (to make it compatible with the following precess steps). Then, a thick photoresist layer (in our case a $75 \mu m$-thick Riston PM275 dry film) is applied on the die and patterned. Finally, the copper posts are electrochemically grown through the openings of the photoresist film, polished to obtain a flat surface, and the photoresist is removed.

In the technique described in [9], a layer of tin $(0.5 \mu \mathrm{m})$ is deposited on top of the posts. This layer is used as a solder between the posts and the copper of the DBC substrate. The die-to-DBC assembly is performed in vacuum, under a pressure of $10 \mathrm{MPa}$ and at a temperature of $200{ }^{\circ} \mathrm{C}$. This results in the diffusion of the tin layer in the copper parts.

Another assembly approach, described in this paper, is to get rid of the tin layer, and to achieve a direct copper-to-copper bonding (that is, to bond the micro-posts to the DBC substrate without any additional material). This technique is promising, as it reduces the number of processing steps. Furthermore, a good thermal performance can be expected, as only copper is used.

\section{Review of the low-temperature direct bonding techniques for Copper}

Packaging techniques used to bond conductive parts usually rely on soldering. Many soldering alloys exist, with various properties (such as their melting temperature), but they all offer medium to low thermal conductivity (less than $50 \mathrm{~W} / \mathrm{K} . \mathrm{m}$ ) [10]. The melting temperature of the solder alloys, which is usually between $200{ }^{\circ} \mathrm{C}$ and $350{ }^{\circ} \mathrm{C}$ also sets a limit to the operating temperature of the whole power module [11]. Furthermore, a power module comprises many layers (figure 1). Such a stack of materials with different CTEs is prone to failure when submitted to temperature cycling.

Therefore, we have tried to get rid of the not-so-conductive layers, as well as to reduce the materials count by bonding directly the copper posts onto the copper metallizations of the substrate. Such a solution is also expected to operate satisfactorily at elevated temperatures, as the melting point of copper $\left(1084{ }^{\circ} \mathrm{C}\right)$ is much higher than that of the classical solder alloys. Copper has attracted much attention in the area of very large scale integration (VLSI) interconnection technology as the most prospective candidate for the conducting material due to its high electrical conductivity and high electromigration resistance compared with aluminium [12], [13]. It is also a material compatible with industrial processes.

Several experiments on $\mathrm{Cu} / \mathrm{Cu}$ direct bonding have been reported [14]-[16]. Although the presented methods are simple, they require either high external pressure and annealing or toxic chemical cleaning processes to achieve a reasonable bonding strength. For example, $\mathrm{Cu}$ wafers exhibit good bonding properties when $\mathrm{Cu} / \mathrm{Cu}$ contacts are carried out at $400{ }^{\circ} \mathrm{C}$ and 4 bar for $30 \mathrm{~min}$, followed by an annealing cure at $400{ }^{\circ} \mathrm{C}$ for $30 \mathrm{~min}$ in $\mathrm{N}_{2}$ atmosphere [17].

Another solution, the so-called Surface Activated Bonding "SAB" process was used to bond $\mathrm{Cu}$-coated wafers at room temperature without any wet chemical process. SAB is a process that joins similar or dissimilar materials by means of the adhesion force between atoms of two atomically clean surfaces under an ultrahigh vacuum (UHV) at room temperature [18], [19]. The same authors also reported that the bonding strength of $\mathrm{Cu} / \mathrm{Cu}$ interface is approximately 6.47 MPa [20]. J. W. Elmer et al. [21] have presented a diffusion bonding of high purity copper using a conventional furnace. A series of diffusion bonds was performed to determine the relationship between bond strength and bonding parameters in order to determine a range of bonding conditions. These tests were made over a wide range of temperature (from $400{ }^{\circ} \mathrm{C}$ to $1000{ }^{\circ} \mathrm{C}$ ), with different bonding pressures and surface states. In these studies, the bonding time was held constant (60 min) at the peak temperature, following a 30 min warming ramp. Bonding strengths of $65 \mathrm{MPa}$ and $190 \mathrm{MPa}$ were found using uniaxial tensile test for samples bonded at $400{ }^{\circ} \mathrm{C}$ and $800{ }^{\circ} \mathrm{C}$ respectively.

In general, a high temperature annealing cure $\left(>400{ }^{\circ} \mathrm{C}\right)$ is required to increase the bonding strength. However, semiconductor devices have been designed to meet the requirement of the existing soldering technology (a few seconds above $300{ }^{\circ} \mathrm{C}$ ). Therefore, an increase in the process temperature could require heavy modification in the dies manufacturing parameters to avoid possible degradation. This is especially 


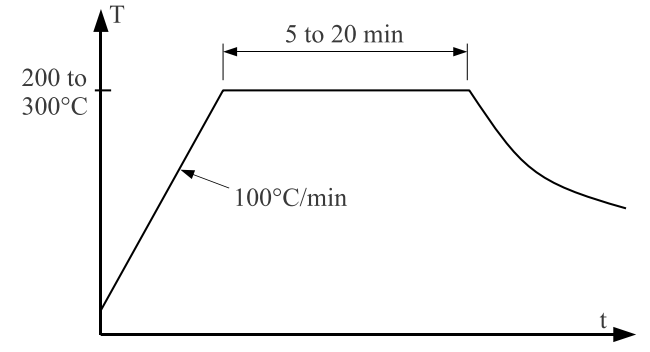

Fig. 2. Temperature profile during the bonding process. Pressure (16 to 76 $\mathrm{MPa})$ and vacuum $\left(10^{-2}\right.$ Torr) are applied during the entire cycle.

true for longer bonding process such as those involving chemical species diffusion, as they last from minutes to hours. In addition, a low temperature process is advantageous in terms of manufacturing costs. Finally, keeping the process temperature to a low level reduces the residual mechanical stresses of the assembly. Therefore, lowering the temperature for $\mathrm{Cu} / \mathrm{Cu}$ direct bonding is a key issue in various future device applications. An alternative solution, which uses an electroless deposit of copper to fill the gap between two copper posts, and thus create a low-temperature bond, is presented in [22]. This technique offers a very good bonding strength (>148 MPa).

The solution presented in this paper is based on a different approach, as no chemical solution is involved during the assembly. To the best of our knowledge, $\mathrm{Cu} / \mathrm{Cu}$ direct bonding using Spark Plasma Sintering (SPS) has never been reported. In this paper, we focus on the bonding issue by evaluating the bonding strength as a function of temperature, pressure and bonding time.

\section{BONDING OF COPPER}

\section{A. Sample Preparation}

Commercial copper rods (Goodfellow, Cambridge, UK, $99.99+\%$ purity) with a diameter of $19 \mathrm{~mm}$ and a length of $400 \mathrm{~mm}$ were used as the base material in the bonding experiment. These rods were cut into $25 \mathrm{~mm}$-long cylindrical pieces with one flat side manually polished. The polishing procedure starts with 220 -grit silicon carbide paper, down to $3 \mu \mathrm{m}$ diamond paste and $0.05 \mu \mathrm{m}$ silica.

The samples were then cleaned to remove the lubricant. The cleaning process found to be successful consisted of (i) ultrasonic cleaning in acetone to remove the lubricant, (ii) ultrasonic cleaning in trichloroethylene, (iii) ultrasonic cleaning in microelectronic grade ethanol, (iv) immersion in 5\% $\mathrm{HF}$ for $1 \mathrm{~min}$ at room temperature for oxide elimination (v) followed by rinsing in DI water and blow drying with nitrogen gas.

\section{B. Bonding Process}

The $\mathrm{Cu} / \mathrm{Cu}$ bonding was carried out with a Spark Plasma Sintering (SPS) system (FCT HPD 25). As with a classical sintering press, a SPS system applies both pressure and heat to the samples. The difference is that the heat is provided by a pulsed DC-current circulating through the graphite die (or through the sample if it is conductive), whereas the

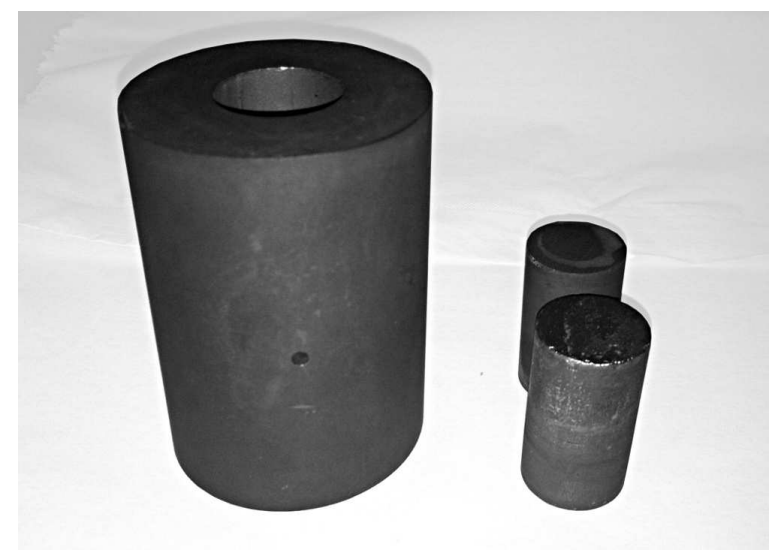

Fig. 3. The graphite die used to bond the copper rods, with the two $20 \mathrm{~mm}$ diameter pressing cylinders.

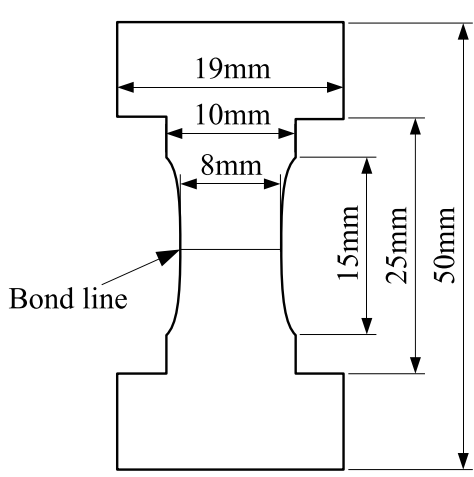

(a)

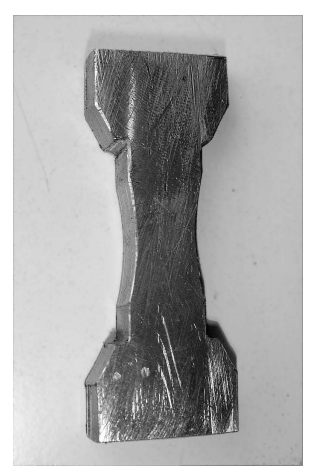

(b)
Fig. 4. Shape (a) and photograph (b) of the samples used for the tensile test.

conventional sintering press uses external heating elements. As a result in the case of the SPS, the heat is generated much closer to the sample, offering very fast temperature dynamics: more than $100 \mathrm{~K} / \mathrm{min}$ for the system used in this study, using current pulses of several $\mathrm{kA}$.

Although not initially designed for the assembly of electronic systems, the SPS technology offers interesting features: its cycle time is comparable to that of a reflow oven (a few minutes) and it operates under vacuum (avoiding oxidation of the copper). SPS systems with platens as large as $30 \mathrm{~cm}(12$ in) in diameter are available, enabling the assembly of several modules at once.

In each experiment, two copper pieces were introduced in a graphite die of $20 \mathrm{~mm}$ inner diameter (figure 3). The bonding was performed in vacuum $\left(10^{-2}\right.$ torr) with temperatures ranging from $200{ }^{\circ} \mathrm{C}$ to $300{ }^{\circ} \mathrm{C}$. The uniaxial force , applied during the bonding and maintained during the cooling down to room temperature, was varied from $5 \mathrm{kN}$ to $24 \mathrm{kN}$ (corresponding to 16 and $77 \mathrm{MPa}$ on the sample respectively). The temperature was measured on the surface of the graphite die using a thermocouple.

The heating rate was fixed to $100 \mathrm{~K} / \mathrm{min}$ and the holding time was varied from 5 to 20 minutes (Figure 2). 


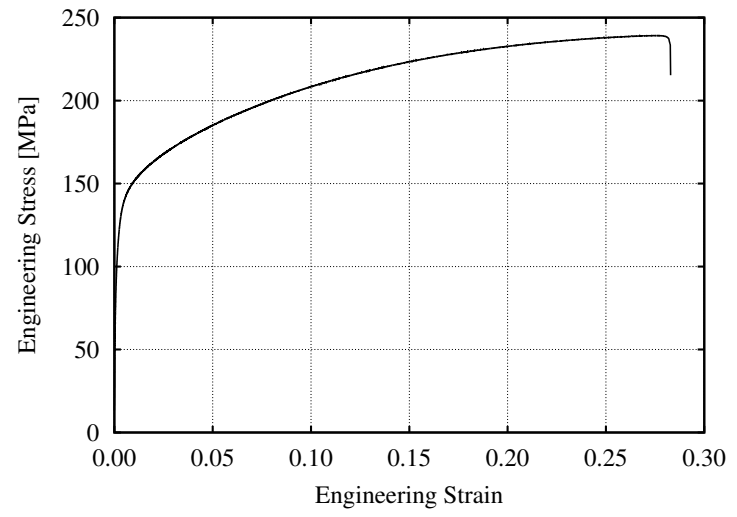

Fig. 5. Tensile test result for one of the sample (sample B in table I).

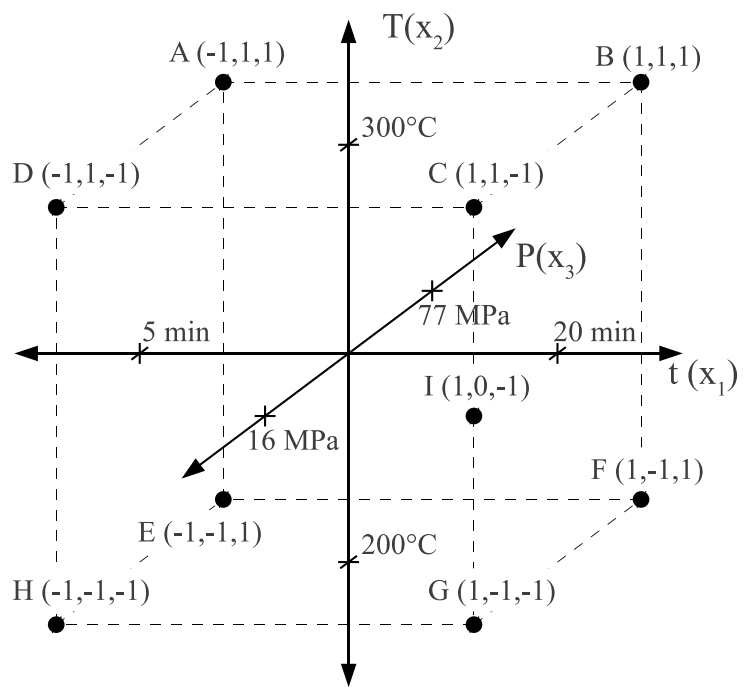

Fig. 6. Position of the experimental points in the $\mathrm{t}, \mathrm{T}, \mathrm{P}$ space

\section{Characterization}

After bonding the samples were machined for the mechanical test (tensile test), as described in figure 4. Mechanical testing of the bonded samples was performed at room temperature using a Lloyd EZ20 tensile machine with a $20 \mathrm{kN}$ cell force. The displacement rate was set up to $1 \mathrm{~mm} / \mathrm{min}$.

Copper being ductile, the sample quickly enters plastic deformation during the tensile test (figure 5). This results in a reduction of the actual section of the sample as it elongates. In this document, a nominal stress value is calculated using the initial surface of the tensile sample. It will thus constitute a lower bound of the true stress experimented on the sample, as plastic deformation and then necking occur before the actual rupture of the sample (hence reducing the surface of the bond). It should be mentioned that all the samples fractured along the bond line (due to the design of the sample).

Surface microstructure observations were studied by a Leitz optical microscope and a scanning electron microscope (SEM Philips XL20).
TABLE I

MEASUREMENT SUMMARY. AS A REFERENCE, A PLAIN COPPER SAMPLE WAS FOUND TO BREAK AT 365 MPA

\begin{tabular}{l|c|c|c|c|c}
$\mathrm{n}^{\circ}$ & Point & $\mathrm{t}(\mathrm{min})$ & $\mathrm{T}\left({ }^{\circ} \mathrm{C}\right)$ & $\mathrm{P}(\mathrm{MPa})$ & $y$ (stress, MPa) \\
\hline 1 & $\mathrm{~A}$ & 5 & 300 & 77 & 181 \\
2 & $\mathrm{~B}$ & 20 & 300 & 77 & 239 \\
3 & $\mathrm{C}$ & 20 & 300 & 16 & 170 \\
4 & $\mathrm{D}$ & 5 & 300 & 16 & 132 \\
5 & $\mathrm{E}$ & 5 & 200 & 77 & 106 \\
6 & $\mathrm{~F}$ & 20 & 200 & 77 & 270 \\
7 & $\mathrm{G}$ & 20 & 200 & 16 & 261 \\
8 & $\mathrm{H}$ & 5 & 200 & 16 & no bond $(0)$ \\
9 & $\mathrm{I}$ & 20 & 250 & 16 & 150 \\
10 & $\mathrm{I}$ & 20 & 250 & 16 & 141 \\
11 & $\mathrm{I}$ & 20 & 250 & 16 & 180 \\
12 & $\mathrm{I}$ & 20 & 250 & 16 & 169 \\
13 & $\mathrm{I}$ & 20 & 250 & 16 & 183
\end{tabular}

\section{PARAMETRIC ANALYSIS}

\section{A. Design of experiment approach}

The cost of the experiments and the availability of the SPS equipment resulted in a limited set of assemblies. A classical $2^{3}$ factorial plan [23], [24] was therefore used to study the effect of three factors (time, temperature, pressure) without making any assumption on which factors or factor combinations are significant.

This factorial plan requires 2 values to be chosen for each factor (one low and one high), resulting in $8\left(2^{3}\right)$ distinct experimental conditions. The position of these 8 points in the $(t, T, P)$ space is presented in figure 6 . The low and high values for $t$ have been chosen to be different enough, yet compatible with a microelectronic assembly process. Values lower than 5 minutes would not have been sufficiently accurate. We considered that $300{ }^{\circ} \mathrm{C}$ is the maximum a semiconductor die can safely withstand. As for the pressure, $16 \mathrm{MPa}$ corresponds to the pressure applied on a $20 \mathrm{~mm}$-diameter sample at the minimum force setting of the press $(5 \mathrm{kN})$. Note that bonding of semiconductor devices at a comparable pressure (or even higher, $40 \mathrm{MPa}$ ) has already been demonstrated successfully [25].

Finally, 5 additional experimental values have been acquired on a different point ( $I$ in figure 6). These points are used to evaluate the accuracy and dispersion of the experimental data. A list of the experiments, with the corresponding tensile strengths measured is given in table I

A simple linear model that takes into account all the interactions between the factors can be expressed as:

$$
\begin{aligned}
y & =a_{0}+\sum_{i=0}^{n} a_{i} x_{i}+\sum_{i=0}^{n} \sum_{j=i+1}^{n} a_{i, j} x_{i} x_{j} \\
& +\sum_{i=0}^{n} \sum_{j=i+1}^{n} \sum_{k=j+1}^{n} a_{i, j, k} x_{i} x_{j} x_{k}+\ldots
\end{aligned}
$$

For a 3-factor case, this can be simplified to

$$
\begin{aligned}
y & =a_{0}+a_{1} x_{1}+a_{2} x_{2}+a_{3} x_{3}+a_{1,2} x_{1} x_{2} \\
& +a_{1,3} x_{1} x_{3}+a_{2,3} x_{2} x_{3}+a_{1,2,3} x_{1} x_{2} x_{3}
\end{aligned}
$$

Where $x_{1}, x_{2}$ and $x_{3}$ are the normalized factors, corresponding respectively to $t, T$ and $P$, and $y$ the tensile stress experienced 
TABLE II

PARAMETERS OF THE MODEL

\begin{tabular}{l|l|c|c|} 
parameter & Coef. & Value & Significant \\
\hline $\bar{y}$ & $a_{0}$ & 165.875 & yes \\
$t$ & $a_{1}$ & 65.125 & yes \\
$T$ & $a_{2}$ & 10.65 & no \\
$P$ & $a_{3}$ & 29.125 & yes \\
$t \cdot T$ & $a_{1,2}$ & -41.125 & yes \\
$t \cdot P$ & $a_{1,3}$ & -9.625 & no \\
$T \cdot P$ & $a_{2,3}$ & 0.375 & no \\
$t \cdot T \cdot P$ & $a_{1,2,3}$ & 14.625 & no
\end{tabular}

by the sample at the breaking point. The normalization of a factor (or parameter) $p$ is calculated as:

$$
x_{i}=\frac{p-\frac{p_{\max }+p_{\min }}{2}}{\frac{p_{\max }-p_{\min }}{2}}
$$

With $p_{\min }$ and $p_{\max }$ the low and high values of the factor $p$ respectively. The normalized values $(1,-1$, or 0$)$ of $t, T$ and $P$ are given for each point in figure 6 .

The model in eq. (2) requires 8 parameters $\left(a_{0} \ldots a_{1,2,3}\right)$ to be identified. This model can be expressed as:

$$
\mathbf{y}=\mathbf{M} \cdot \mathbf{a}
$$

Where $\mathbf{y}$ is the column matrix that contains the tensile strengths for points $\mathrm{A}$ to $\mathrm{H}$ (see table I), a the column matrix that contains the parameters $a_{0} \ldots a_{1,2,3}$ to be calculated and M a matrix that contains the values of the 3 factors and their combinations, for each of the 8 experimental points. Each row of $\mathbf{M}$ corresponds to the coefficients of (2): $x_{0}$ (constant factor associated with $a_{0}$ in eq. (2), always equal to 1 ), $x_{1}$ (normalized factor $t$ ), $x_{2}(T), x_{3}(P), x_{1} x_{2}, x_{1} x_{3}$, $x_{2} x_{3}, x_{1} x_{2} x_{3}$ :

$$
\left[\begin{array}{l}
y_{A} \\
y_{B} \\
y_{C} \\
y_{D} \\
y_{E} \\
y_{F} \\
y_{G} \\
y_{H}
\end{array}\right]=\left[\begin{array}{rrrrrrrr}
1 & -1 & 1 & 1 & -1 & -1 & 1 & -1 \\
1 & 1 & 1 & 1 & 1 & 1 & 1 & 1 \\
1 & 1 & 1 & -1 & 1 & -1 & -1 & -1 \\
1 & -1 & 1 & -1 & -1 & 1 & -1 & 1 \\
1 & -1 & -1 & 1 & 1 & -1 & -1 & 1 \\
1 & 1 & -1 & 1 & -1 & 1 & -1 & -1 \\
1 & 1 & -1 & -1 & -1 & -1 & 1 & 1 \\
1 & -1 & -1 & -1 & 1 & 1 & 1 & -1
\end{array}\right] \cdot\left[\begin{array}{c}
a_{0} \\
a_{1} \\
a_{2} \\
a_{3} \\
a_{1,2} \\
a_{1,3} \\
a_{2,3} \\
a_{1,2,3}
\end{array}\right]
$$

As $\mathbf{M}^{T} \cdot \mathbf{M}=n \mathbf{I}$, with $n$ the size of the matrix $\mathbf{M}$ (in our case, $n=8$ ), a can be calculated as:

$$
\mathbf{a}=\frac{1}{n} \mathbf{M}^{T} \mathbf{y}
$$

An expanded version of (6) for $n=8$ is given in (7), with $y_{A} \ldots y_{H}$ the tensile stress measured for points $A \ldots H$ respectively. The calculated values of $a_{0}$ to $a_{1,2,3}$ are listed in table II.

\section{B. Model accuracy}

5 samples were assembled at the same experimental point $I$ (see table I) in order to characterize the reproducibility and accuracy of the bonding process and of the tensile tests. From these measurements, a tensile strength value of $164.4 \pm 20 \%$ was calculated for point $I$.

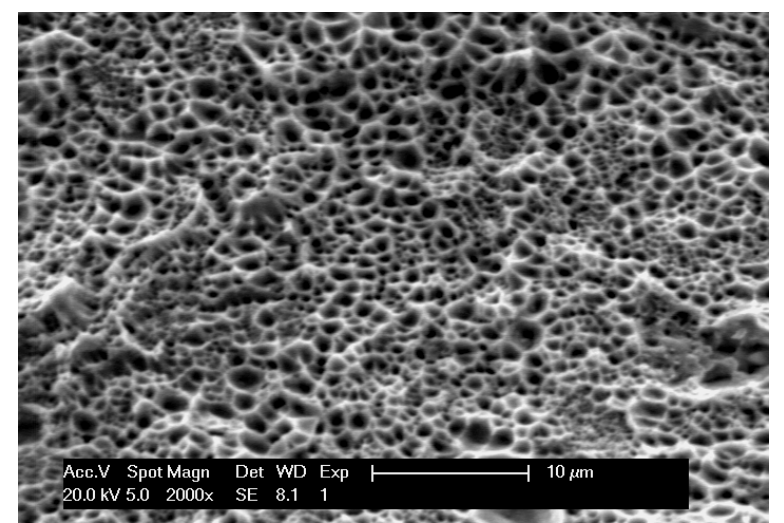

Fig. 8. SEM image of the fracture surface (after tensile test), for a sample bonded at $300{ }^{\circ} \mathrm{C}$ for 20 minutes and with a pressure of $16 \mathrm{MPa}$.

This fairly large tolerance is due to the low sample count, as well as to the low reproducibility of the tensile tests: a much bigger number of samples is usually required but this was unpractical in our case.

A diagram of the influence of each factor is given in figure 7 . This diagram is obtained by using the data in table I (points A to $\mathrm{H}$ ). For each sub-graph, two data set are formed (one for both values of the corresponding factor, i.e 1 or -1), and the average value of $y$ is calculated for each set. As an example, for the first sub-plot $(t)$, the two dataset correspond to $t=5 \mathrm{~min}$ (points $\mathrm{A}, \mathrm{D}, \mathrm{E}, \mathrm{H}$ ) and 20 min respectively (points B, C, F, G).

Considering the $\pm 20 \%$ accuracy, only few parameters in table II are significant: $a_{0}$ (the average tensile strength for all samples), $a_{1}$ (effect of time), $a_{3}$ (effect of the pressure) and $a_{1,2}$ (conjugated effect of time and temperature).

Therefore, the model (2) can be simplified as:

$$
\begin{aligned}
y & =a_{0}+a_{1} x_{1}+a_{3} x_{3}+a_{1,2} x_{1} x_{2} \\
& =166+65 x_{1}+29 x_{3}-41 x_{1} x_{2}
\end{aligned}
$$

Applying this model to the parameters of point $\mathrm{I}$ in table I $\left(t=20 \mathrm{~min}, T=250^{\circ} \mathrm{C}, P=16 \mathrm{MPa}\right.$, or $x_{1}=1$, $x_{2}=0, x_{3}=-1$ respectively), yields a tensile strength of $202 \pm 40 \mathrm{MPa}$. This is compatible with the tensile strength measured at point I $(164.4 \pm 20 \%)$, but the precision of the results is too low to conclude about the suitability of our linear model. More data points would be needed to improve the accuracy.

\section{DISCUSSION}

Even with the limited variation range for all three factors (5-20 minutes, 200-300 ${ }^{\circ} \mathrm{C}$, and 16-77 MPa), substantial differences were found in tensile strength. In most cases, however, a very good bond was formed: the tensile strength of the used bulk copper-rod was found to be $365 \mathrm{MPa}$, while most results in table I are over $122 \mathrm{MPa}$ (a third of the bulk value).

Another evidence of the good bond quality is visible in figure 8: the fracture surface is characteristic of ductile fracture with the presence of dimples. This means that the sample has been heavily deformed, which is also exhibited by the large 


$$
\left\{\begin{aligned}
a_{0} & =\frac{1}{8}\left[y_{A}+y_{B}+y_{C}+y_{D}+y_{E}+y_{F}+y_{G}+y_{H}\right] \\
a_{1} & =\frac{1}{8}\left[-y_{A}+y_{B}+y_{C}-y_{D}-y_{E}+y_{F}+y_{G}-y_{H}\right] \\
& \vdots \\
a_{1,2,3} & =\frac{1}{8}\left[-y_{A}+y_{B}-y_{C}+y_{D}+y_{E}-y_{F}+y_{G}-y_{H}\right]
\end{aligned}\right.
$$

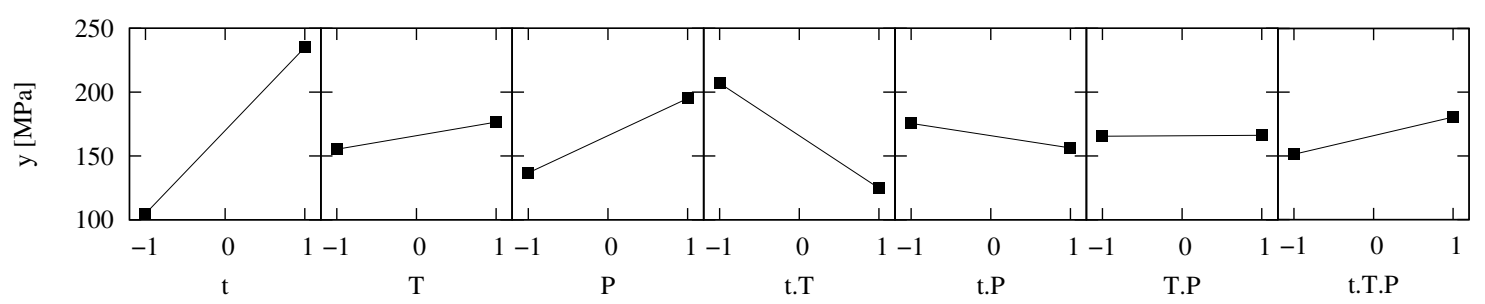

Fig. 7. Influence of the factors time $(t)$, temperature $(T)$, pressure $(P)$ and their interactions on the tensile strength $y$. This shows that the most important factors are the time, pressure, and the interaction between time and temperature $(\mathrm{t}, \mathrm{T})$.

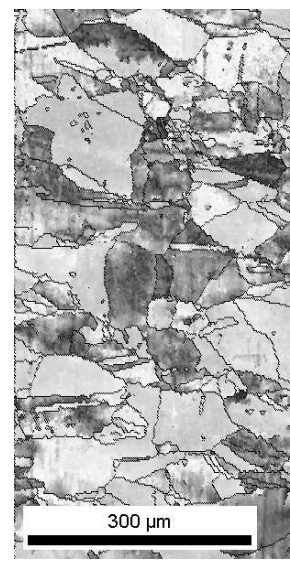

(a)

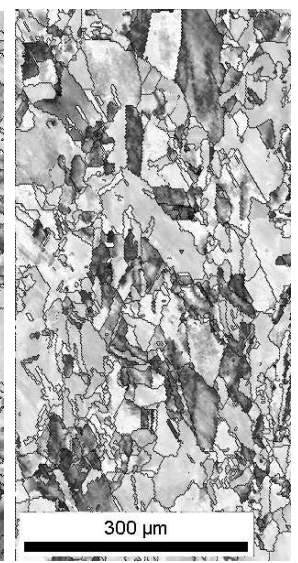

(b)

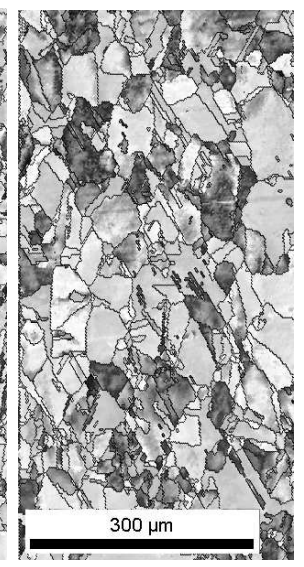

(c)
Fig. 9. EBSD pictures of three samples captured just below the bonding line, with the samples standing upright, bonded for 20 minutes, under a pressure of $16 \mathrm{MPa}$, and a temperature of $200^{\circ} \mathrm{C}$ (a), $250^{\circ} \mathrm{C}$ (b) and $300^{\circ} \mathrm{C}$ (c). This shows a much bigger grain size for the sample bonded at $200^{\circ} \mathrm{C}(101 \mu \mathrm{m}$ average) than for $250^{\circ} \mathrm{C}(46 \mu \mathrm{m})$ or $300^{\circ} \mathrm{C}(50 \mu \mathrm{m})$.

strain value attained during the tensile tests (as can be seen for example in figure 5). Similar patterns were found over the entire fracture surface and for all samples.

From the model in (2), it can be seen that time $\left(x_{1}\right)$ and pressure $\left(x_{3}\right)$ have the expected effect: an increase in either of these parameters results in a stronger bond.

The negligible influence of temperature and the negative effect of the simultaneous increase of time and temperature can firstly be surprising, but can actually be explained by the following considerations: in these tests, a good bond could be achieved for any temperature or time value. However, the application of temperature to the samples also constitutes a heat treatment of the copper. The effect of such treatment on work hardened copper is a change in its microstructure. For example, increasing the temperature from $200{ }^{\circ} \mathrm{C}$ to $300{ }^{\circ} \mathrm{C}$ would involve further annealing and recrystallization of the sample, decreasing its overall mechanical properties. This point is beyond the scope of this paper, but the Electron Backscatter Diffraction (EBSD) images shown in figure 9

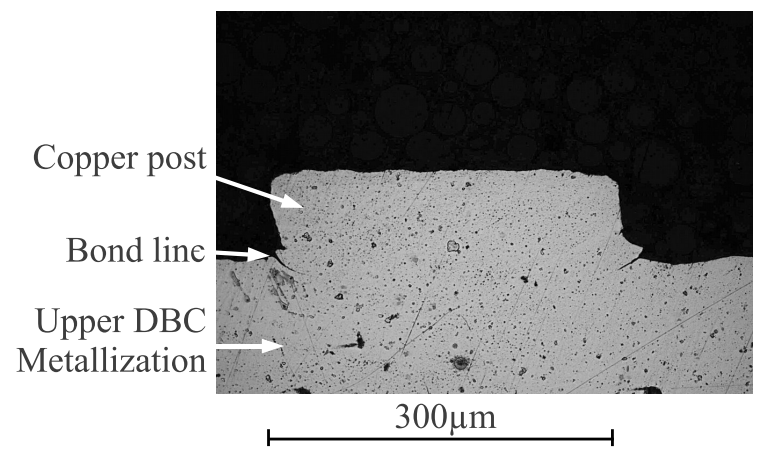

Fig. 10. Example of a micropost bonded onto a DBC substrate. This post is part of a diode-to-DBC bonding experiment in which the interface between the posts and the diode was found to be defective. The copper-to-copper bond, however, is of very good quality. The bond line only visible at the edges of the assembly.

demonstrate that the crystallographic structure of the copper changes with the bonding parameters. Therefore, the decrease in mechanical strength is mainly caused by the reduction in the intrinsic mechanical properties of the copper rather than by the bond itself. This is confirmed by the ductile fracture surfaces observed on all samples.

Finally, a test structure comprising a silicon power diode $(12.7 \times 12.7 \mathrm{~mm}$ die size $)$ with copper posts electroplated on one side, placed between two DBC substrates, was assembled. This test structure comprises two insulating layers (the ceramic layers of the DBCs). The voltage applied by the SPS equipment is in the order of $4 \mathrm{~V}$, much lower than the dielectric strength of the ceramic layers (several kilovolts). Therefore, it was expected that the path of the heating current in the SPS press would differ dramatically from the conductive (copper) samples in figure 4(b). As a result, this could have a strong effect on the bonding.

The copper posts were successfully bonded on the copper layer of the DBC (a close-up cross-section is shown in figure 10). However, the post-to-die interface was found to be weak and failed, which is why no diode is visible in the figure. This issue is related to the processes prior to the copper plating, and is therefore beyond the scope of this paper. It 
is important to note that the electrical performances of the diode were not degraded in the assembly process. This test demonstrates that a complex structure including conductive layers, but also insulating layers and semiconductor devices, can be successfully bonded using the technique presented here.

\section{CONCLUSION}

The copper-to-copper bonding technique that is presented is compatible with the requirements of the application: a semiconductor die can sustain temperatures up to $300^{\circ} \mathrm{C}$ for a few minutes and pressures in the order of a few tens of MPa.

A bonding strength higher than previously reported in the literature was found (between a third and more than two thirds of the bulk copper tensile strength). Furthermore, this good bond was obtained for temperatures as low as $200^{\circ} \mathrm{C}$. A study is currently being carried out to understand the physics of this bonding process. In particular, the effect of the intense electrical current used for the SPS heating is under investigation.

Based on this bonding technique, a "sandwich" structure comprising a silicon die and two DBC substrates was assembled. A bond was observed between the copper posts of the die and the copper of the DBC, even with the ceramic layers of the substrates forming an electrical insulation around the parts to be bonded. This proves the feasibility of the technique for 3D packaging applications.

\section{ACKNOWLEDGMENT}

The authors would like to thank the Agence Nationale de la Recherche for their financial support of this work under the project grant ECLIPSE.

They are also pleased to acknowledge important contributions used in the body of this work from G. Bonnefont and F. Mercier from MATEIS for SPS processing, as well as to thank M. Perez from MATEIS for fruitful discussions.

\section{REFERENCES}

[1] A. Hamidi and D. Cottet, "Parasitics in power electronics packaging," in $37^{\text {th }}$ International Symposium on Microelectronics, IMAPS. Long Beach, California, USA: IMAPS, nov 2004.

[2] S. Dieckerhoff, T. Kirfe, T. Wernicke, C. Kallmayer, A. Ostmann, E. Jung, B. Wunderle, and H. Reichl, "Electric Characteristics of Planar Interconnect Technologies for Power MOSFETs," in Power Electronics Specialists Conference, 2007. PESC 2007. IEEE, jun 2007, pp. 1036 -1042 .

[3] P. Ning, T. Lei, F. Wang, G.-Q. Lu, and K. Ngo, "A Novel HighTemperature Planar Package for SiC Multi-Chip Phase-Leg Power Module," in Applied Power Electronics Conference and Exposition, 2009. APEC 2009. Twenty-Fourth Annual IEEE, feb 2009, pp. 2061 $-2067$.

[4] C. Gillot, C. Schaeffer, C. Massit, and L. Meysenc, "Double-Sided Cooling for High Power IGBT Modules Using Flip Chip Technology," IEEE Transaction on Components and Packaging Technology, vol. 24, no. 4, pp. 698-704, dec 2001.

[5] C. Buttay, J. Rashid, C. Johnson, F. Udrea, G. Amaratunga, P. Ireland, and R. Malhan, "Compact Inverter Designed for High-Temperature Operation," in Proc. IEEE Power Electronics Specialists Conference PESC 2007, 2007, pp. 2241-2247.

[6] R. Markus, A. Schletz, and M. März, "Study on Advanced cooling with focus on double-sided cooling," ECPE, ECPE e.V. Landgrabenstr. 9490443 Nürnberg, technology survey, juil 2008. [Online]. Available: www.ecpe.org
[7] L. Ménager, C. Martin, B. Allard, and V. Bley, "Industrial and lab-scale power module technologies : A review," in Proceedings of the 32nd Annual Conference of the IEEE Industrial Electronics Society (IECON), IEEE, Ed., Paris, France, nov 2006.

[8] J. Schulz-Harder, "Review on Highly Integrated Solutions for Power Electronic Devices," in Proceedings of the Conference on Integrated Power electronics Systems (CIPS), Nüremberg, mar 2008, p. 7 p. [Online]. Available: http://www.electrovac.com/sprache2/n221666/n. html

[9] L. Ménager, M. Soueidan, B. Allard, V. Bley, and B. Schlegel, "A Lab-Scale Alternative Interconnection Solution of Semiconductor Dice Compatible with Power Modules 3D Integration," IEEE Transactions on Power Electronics, vol. 25, no. 7, pp. 1667-1670, jul 2010.

[10] W. W. Sheng and R. P. Colino, Power Electronic Modules: Design and Manufacture, 1st ed. CRC, jun 2004.

[11] K. Guth, D. Siepe, J. Görlich, H. Torwesten, R. Roth, F. Hille, and F. Umbach, "New assembly and interconnects beyond sintering methods," in Proceedings of PCIM, Nuremberg, may 2010, pp. 232-237.

[12] T. Nitta, T. Ohmi, T. Hoshi, S. Sakai, K. Sakaibara, S. Imai, and T. Shibata, "Evaluating the Large Electromigration Resistance of Copper Interconnects Employing a Newly Developed Accelerated Life-Test Method," Journal of The Electrochemical Society, vol. 140, no. 4, pp. 1131-1137, 1993. [Online]. Available: http://link.aip.org/link/ ?JES/140/1131/1

[13] P.-L. Pai and C. Ting, "Selective electroless copper for VLSI interconnection," Electron Device Letters, IEEE, vol. 10, no. 9, pp. $423-425$, sep. 1989 .

[14] A. Fan, A. Rahman, and R. Reif, "Copper Wafer Bonding," Electrochemical and Solid-State Letters, vol. 2, no. 10, pp. 534-536, 1999. [Online]. Available: http://link.aip.org/link/?ESL/2/534/1

[15] K. Chen, C. Tan, A. Fan, and R. Reif, "Copper bonded layers analysis and effects of copper surface conditions on bonding quality for three-dimensional integration," Journal of Electronic Materials, vol. 34, pp. 1464-1467, 2005, 10.1007/s11664-005-0151-0. [Online]. Available: http://dx.doi.org/10.1007/s11664-005-0151-0

[16] Y. A. Li, R. W. Bower, and I. Bencuya, "Low Temperature Copper to Copper Direct Bonding," Japanese Journal of Applied Physics, vol. 37, no. Part 2, No. 9A/B, pp. L1068-L1069, 1998. [Online]. Available: http://jjap.jsap.jp/link?JJAP/37/L1068/

[17] K.-N. Chen, A. Fan, and R. Reif, "Microstructure examination of copper wafer bonding," Journal of Electronic Materials, vol. 30, pp. 331-335, 2001, 10.1007/s11664-001-0039-6. [Online]. Available: http://dx.doi.org/10.1007/s11664-001-0039-6

[18] H. Takagi, K. Kikuchi, R. Maeda, T. R. Chung, and T. Suga, "Surface activated bonding of silicon wafers at room temperature," Applied Physics Letters, vol. 68, no. 16, pp. 2222-2224, 1996. [Online]. Available: http://link.aip.org/link/?APL/68/2222/1

[19] H. Takagi, R. Maeda, N. hosoda, and T. Suga, "Transmission Electron Microscope Observations of Si/Si Interface Bonded at Room Temperature by Ar Beam Surface Activation," Japanese Journal of Applied Physics, vol. 38, no. Part 1, No. 3A, pp. 1589-1594, 1999. [Online]. Available: http://jjap.jsap.jp/link?JJAP/38/1589/

[20] T. H. Kim, M. M. R. Howlader, T. Itoh, and T. Suga, "Room temperature $\mathrm{Cu}-\mathrm{Cu}$ direct bonding using surface activated bonding method," Journal of Vacuum Science \& Technology A: Vacuum, Surfaces, and Films, vol. 21, no. 2, pp. 449-453, 2003. [Online]. Available: http://link.aip.org/link/?JVA/21/449/1

[21] J. W. Elmer, J. Klingmann, and K. Van Bibber, "Diffusion bonding and brazing of high purity copper for linear collider accelerator structures," Phys. Rev. ST Accel. Beams, vol. 4, no. 5, p. 053502, May 2001.

[22] A. He, T. Osborn, S. A. Bidstrup Allen, and P. A. Kohl, "Low-Temperature Bonding of Copper Pillars for All-Copper Chipto-Substrate Interconnections," Electrochemical and Solid-State Letters, vol. 9, no. 12, pp. C192-C195, 2006. [Online]. Available: http: //link.aip.org/link/?ESL/9/C192/1

[23] P. Dagnelie, Principes d'expérimentation - Planification des expériences et analyse de leurs résultats, electronic edition, in french ed. Gembloux: les presses agronomiques de Gembloux, 2003. [Online]. Available: http://www.dagnelie.be

[24] L. Dascalescu, K. Medles, S. Das, M. Younes, L. Caliap, and A. Mihalcioiu, "Using Design of Experiments and Virtual Instrumentation to Evaluate the Tribocharging of Pulverulent Materials in Compressed-Air Devices," IEEE Transactions on Industry Applications, vol. 44, no. 1, pp. 3-8, jan 2008.

[25] C. Göbl, P. Beckedahl, and H. Braml, "Low temperature sinter technology Die attachment for automotive power electronic applications," in Automotive Power Electronics, Paris, 21-22 jun 2006, 
p. 5. [Online]. Available: www.semikron.com/internet/webcms/objects/ pdf/APE2006_Goebl.pdf 